\title{
Using Gamification in a Teaching Innovation Project at the University of Alcalá: A New Approach to Experimental Science Practices
}

\author{
Dolores López Carrillo ${ }^{1}$, Amelia Calonge García ${ }^{1}$, Teresa Rodríguez Laguna ${ }^{1}$, Germán Ros \\ Magán ${ }^{1}$ and José Alberto Lebrón Moreno ${ }^{2}$ \\ ${ }^{1}$ University of Alcalá, Guadalajara, Spain \\ ${ }^{2}$ CUCC Center, University of Alcalá, Alcalá de Henares, Spain \\ mariadolores.lopez@uah.es \\ a.calonge@uah.es \\ mayte.rlaguna@uah.es \\ german.ros@uah.es \\ alberto.lebron@cardenalcisneros.es \\ DOI: 10.34190/JEL.17.2.03
}

\begin{abstract}
Pre-service teachers frequently express negative prejudices towards science and the methodologies traditionally used during their training. Gamification is a booming technology based on combining the psychological aspects, mechanics and dynamics of a game in non-ludic environments. The use of gamification has shown good outcomes in terms of increasing students' motivation towards the sciences. In this study, new laboratory practices were developed under the umbrella of gamification methodology for pre-service teachers. The general objectives were to eliminate negative prejudices, fear and rejection attitudes towards science, to foster the conceptual and procedural learning of science among students and to provide students with real-life examples and an experience of applying gamification themselves. First, the theoretical basis of the main components and dynamics of gamification in the Education context are summarized. Secondly, their application in a specific subject from the curriculum for the Teaching Training in Primary Education degree (Didactics of Natural Science (DNS), 3rd year) are presented. The methodology was applied twice in laboratory practice in two consecutive academic years: 2017/2018 (5 groups, 150 students) and 2018/2019 (6 groups, 183 students). The steps, dynamics, components and the tools used for the gamification experience are described (i.e. Kahoot, Class Dojo). Several pre and post-tests were carried out to explore: (i) the students' relationship with games; (ii) their preferred role as players; (iii) their assessment of the different elements involved in the gamification methodology; (iv) their motivation towards science laboratories attitude and $(v)$ their self-perception with regards to their newly acquired skills to put gamification into practice in their professional future.
\end{abstract}

Keywords: motivation, gamification, teaching training, laboratory practices, Kahoot, ClassDojo

\section{Introduction}

Gamification applies elements related to game theory and mechanics, such as the use of prizes and rewards, to increase the user engagement and motivation, in not traditionally ludic contexts. Up to now, these techniques have been successfully applied mainly in the business field, including new technologies and in mobile applications. One of the flourishing application fields of gamification in the past few years is education, shifting the passive learning process perspective, turning students into active protagonists of the process, to achieve specific goals. Motivation is an essential element in the teaching-learning process. One of the objectives of teaching innovation is to prove that the traditional teaching methods, where students have a passive role, do not work in an optimal way. In contrast, a well-designed game applied in the education context, is a 'guided missile' to the motivational heart of the human psyche (Werbach and Hunter, 2012).

Our goal was to apply gamification theories to develop a series of laboratory practices in different scientific areas, such as Biology, in future teachers, during their training at university. Based on the students age and their social environment, we want to evaluate well-designed gamification tools as an effective technique to apply in the laboratory or in the classroom. This paper describes a methodology based on gamification (as an alternative to traditional passive teaching) to strengthen students' motivation and engagement and increase their commitment to their own teaching-learning process. A pilot trial was carried out on two 3rd year university students promotions (Teaching Training Degree in Primary Education, University of Alcala (Spain)). Our main objectives were (1) To determine the effectiveness of the motivation and engagement through 
gamification in the laboratory sessions; (2) To establish whether applying gamification improved the way in which students learnt compared to other non-gamified laboratory practical sessions. In particular, gamification was applied to teach science laboratory practices (one of the sessions for Biology and Geology), in the subject of Didactics of Natural Sciences (DNS). Through this particular application, we will show the methodology and implementation of gamification in education, defining the basic elements needed to design a project based on palynology. This paper is an extension of our work presented in the proceedings of the 17th European Conference on E-learning (Lopez Carrillo et al., 2018).

\section{Gamification in education, motivation to learn science}

The term gamification was used for the first time in 2002 by Nick Pelling, but it did not begin to gain popularity until 2010 (Rodríguez and Santiago, 2015). These authors define gamification in the following way: "... Gamification is understood as the process by which mechanics and game design techniques are extended, to seduce and motivate the audience in the attainment of certain objectives ... or," ... gamification is to bring the different mechanics and techniques found in games to contexts that have nothing to do with them to try to solve real problems ... "(Rodríguez and Santiago, 2015, p.5).

Sánchez (2015) endorses the view that gamification is directly associated with the technologies of the ludic field such as video games. Another point for agreement for Rodríguez and Santiago (2015), Zichermann and Cunningham (2011), and Dicheva, Dicheva, Agre and Angelova (2015) is the goal of motivating and engaging through gamification.

Although gamification had its heyday due to the rise of new technologies and mobile applications, it does not mean that it should be restricted to these fields. In fact, it can be approached from the use of such basic resources as a sheet of paper, or the use of an application or a screen to carry it out (Kim, 2015). Morris, Croker, Zimmerman, Gill and Romig in 2012 analyzed the idea of gamification applied to science education, based on the results of cognitive psychology research and development, and educational research to provide guidance in the use of existing games and develop new games to facilitate scientific thinking ascribed to the science curriculum.

As mentioned before, to 'gamify' in education means applying techniques based on games and videogames to motivate students and encourage their positive progress. The fact of making use of these ideas in the Teaching Training Degree in Primary Education, in order to turn the teaching task into something attractive and dynamic, makes the student have fun and learn in a meaningful scientific context. Similarly, Morris et al (2012) also suggest that scientific education can be improved by incorporating the key characteristics of games that influence motivation, cognition and metacognition. Therefore, it is a very effective tool that helps to get the students' attention, to motivate them, to get them committed to a mission and can even influence their behaviour (Kim, 2015). If this technique helps people to save energy, take care of the environment or improve road safety, why not use it to help learning in a more dynamic and attractive way?

To be able to study motivational mechanisms and to design a suitable gamified practice, we focus on the research by Sailer, Hense, Mandl and Klevers (2013). These authors show through a theoretical study how the components of gamification can be a motivation taking into account the type of player the game is aimed at.

Consequently, the elements to promote motivation are:

1. Leaderboards and badges if we talk about highly competitive players and players who are more involved in the game with passing tests, as well as those that are integrated into a team.

2. Points and rewards. The motivation will be encouraged from a behavioural learning perspective. The players provide an immediate feedback through these elements.

3. Missions and badges. These elements favour motivation because they generate clear and achievable results for the players.

4. Challenges, history and avatars. These elements motivate players who need the experience through feeling of competence, or autonomy as well as the feeling of social relationship.

5. Significant stories, assumptions. We can improve the motivation through the fulfillment of the interests of the players. We can awake the interest in the situational context. Players will also be motivated if gamification improves the flow sensation with a clear objective. It allows the flow sensation to adapt the level of difficulty for individual skills and competences. 
6. And finally, from the emotion perspective, and this is what we consider as the most important point, the use of elements such as Challenges, Meaningful stories and the feeling of belonging to a group: these elements motivate players to diminish the negative feelings they tend to have in the subjects of a scientific nature (as already mentioned before). These elements are considered to favour feelings of sympathy and pleasure when they are used for the design of a story.

\section{Steps to gamify laboratory practices}

Morris et al. (2012) and Werbach and Hunter (2012) not only argue the possibility of being able to provide a significant scientific learning through this technique but also provide the basis to be able to organize and structure it so that it can be applied in non-ludic environments. Taking into account that the term gamification has been addressed theoretically up to now, we are going to establish which features are indispensable to gamify contents and how we can gamify a practical content. To gamify, the game or dynamics that is intended to be developed must be properly designed to achieve the objectives and educational-training competences.

Werbach and Hunter (2012) propose a series of categories of relevant game elements in order to be able to gamify any situation, not related to the game. These categories are the dynamics, the mechanics and the gamification components.

According to these authors, the highest level of abstraction would be the dynamics that will facilitate the progress of the student as well as the achievement of the proposed objectives. These dynamics integrate elements that allow the structure and development of the game to be justified and designed, in this case, that of a laboratory practice. Within this category the argumentative line, the progress and the relations between the student-players are established. For Werbach and Hunter (2012) the mechanics refer to the basic processes that will allow the development of the action (practice). Therefore, it can be stated that it is the way to develop one or more dynamics. Within the mechanics of the game we talk about competition, challenges, cooperation, rewards, chance ... Finally, the components are probably the most visible elements of gamification because they are more specific and motivating. However we must not forget that they will not work if they are not included in an adequate and well managed dynamic by their mechanics. Thus within these components there is great diversity: achievements-goals, avatars, emblems, missions, collections, combats, levels, points, progress charts...

Nah, Zeng, Telaprolu, Ayyappa and Escheenbrenner (2014) conducted a literature review on what are the essential components and what different gamification proposals in education have in common. After identifying the characteristic elements that are needed to gamify, different connections must be established between these elements. Thus, Dicheva et al. (2015) contrast the gamification components and their vision from the different perspectives proposed. For example, one of the most popular elements that has already been cited are the "badges". According to Detering, Dixon, Khaled and Nacke (2011) badges are considered as a pattern of game interfaces; Zichermann and Cunningham (2011) and losup and Epema (2014) identify them as game mechanics, and Hamari, Koivisto and Sarsa (2014) speak of a motivational element. Therefore, it is clear that their classification and use may vary within the terminology, depending on the author.

Once the necessary elements to implement the technique have been established, it is important to design a procedure to do it. Werbach and Hunter (2012) propose up to six steps to implement gamification properly:

- Define the objectives. What do you want to achieve?

- Outline the objective behaviours. How are you going to get it?

- Describe the players. Who should get it?

- Develop activity cycles. How are you going to work to get it?

- Do not forget to enjoy.

- Implement the appropriate tools.

We only talk about the components of gamification in the final step. Steps 1 to 4 are defined in the practice script since they are the essential elements of any educational program and will be discussed later in more detail (Figure 1). 


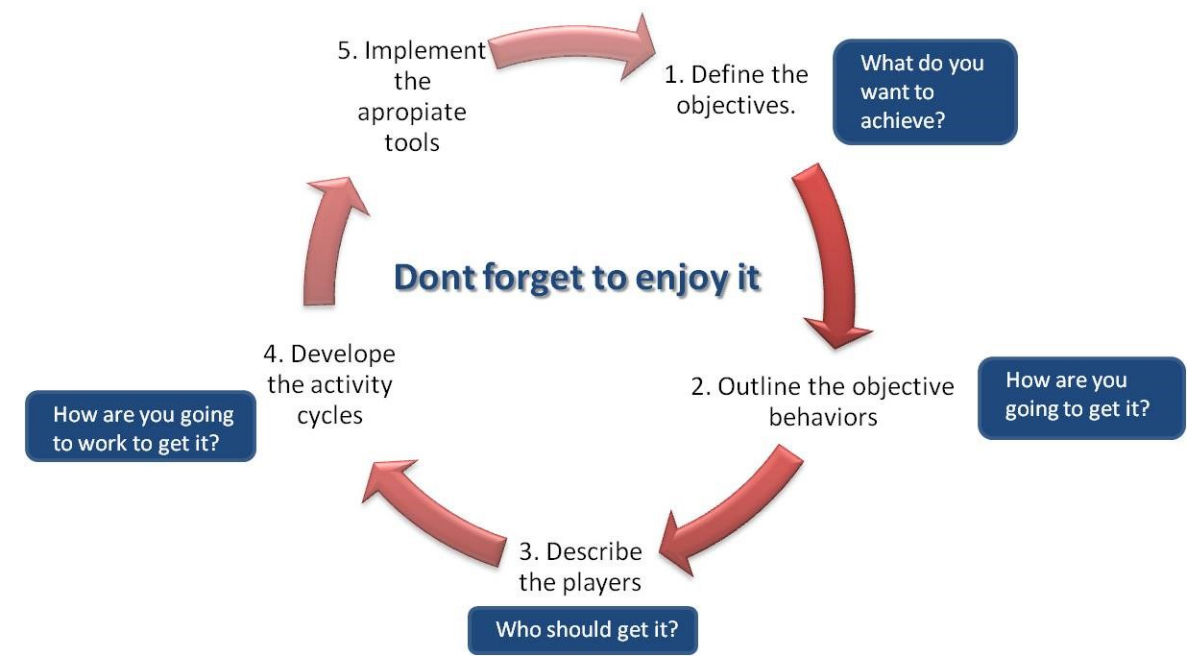

Figure 1: Gamify steps (based on Werbach and Hunter, 2012)

This study is aimed at designing a laboratory practice of two hours duration in the Didactics of Natural Science (DNS) subject of the degree in Teaching Training in Primary Education where students are being trained on how to teach biology content (palynology in particular) to pupils between 6 and 12 years of age.To do it, is important to follow the previous steps proposed by Werbach and Hunter (2012) to gamify a specific content, as well as the several elements of the games and videogames that Sailer et al (2013) propose to motivate according to the type of player and the objective to achieve.

\section{Methodology}

To design a gamify practice that allows to increase motivation, as well as learning, we need to know the type of players we will work with. Hence, this study has focused on obtaining both quantitative and qualitative data.

Since the ultimate goal is not only to check if and how a laboratory practice can be gamified, in addition we need to check that the motivation keeps the interest to develop this and it can encourage the learning of scientific contents.

While the qualitative data are focused on getting feedback from students participating in the study, through the quantitative data we want to see that the motivation has worked and has aroused the interest to learn. To collect all these data we used Google forms because the use of innovative instruments such as online forms of open access through mobile devices gives students a positive image of innovation and topicality (GarcíaTormo, 2018).

\subsection{Target group of students}

During the academic year 2017/18 a single test was done, while for the course 2018/19 it was extended to two forms in order to obtain more significant data: a pretest and a posttest. In the last case (2018/19):

- The initial form allows collecting data about the type of player and level of knowledge before to the test.

- The final form allows verifying the assimilation of the specific knowledge and competences, being able to show the progress in the learning and, therefore, showing the effectiveness of the same (García-Tormo, 2018).

The gamify practice has been developed during the course $2017 / 18$, with a total of 150 students $(n=150)$, and 183 students $(n=183$ ) in the course 2018/19. All the students belonged to the 3rd year of the Teaching Training Degree in Primary Education in different specialties or modalities. They are mostly 20-year-old students who are preparing to become primary school teachers. The laboratory practice that has been developed belongs to a subject devoted to teaching science. In this subject the students must learn not only the essential scientific competences (that any teacher should know) but must know the different tools and methods for their teaching, including the most innovative and technological ones. 
As for preliminary data, we can establish that all participants in both academic years (Figure 2) are students who have had enough contact with board games, role-playing games or videogames; therefore, they are familiar with this 'playful' environment and its elements. Both in this course and in the following courses, the students are more familiar with manipulative board games (41\% in $2017 / 18$ and $59 \%$ in $2018 / 19$ ), but there is also a high percentage of students familiar with playing video games (37\% in 2017/18 and 32\% in 2018/19).

Moreover, if we want to measure the frequency with which they play, we can say that of 129 students a $7.8 \%$ play every day, and a $15.5 \%$ play every week, so nearly a quarter of our sample are regular weekly or daily players in 2018/19, although most are sporadic.

With this data, it seems understandable to think that the approach of a laboratory practice based on elements of the game might be of interest or draw attention of our students.
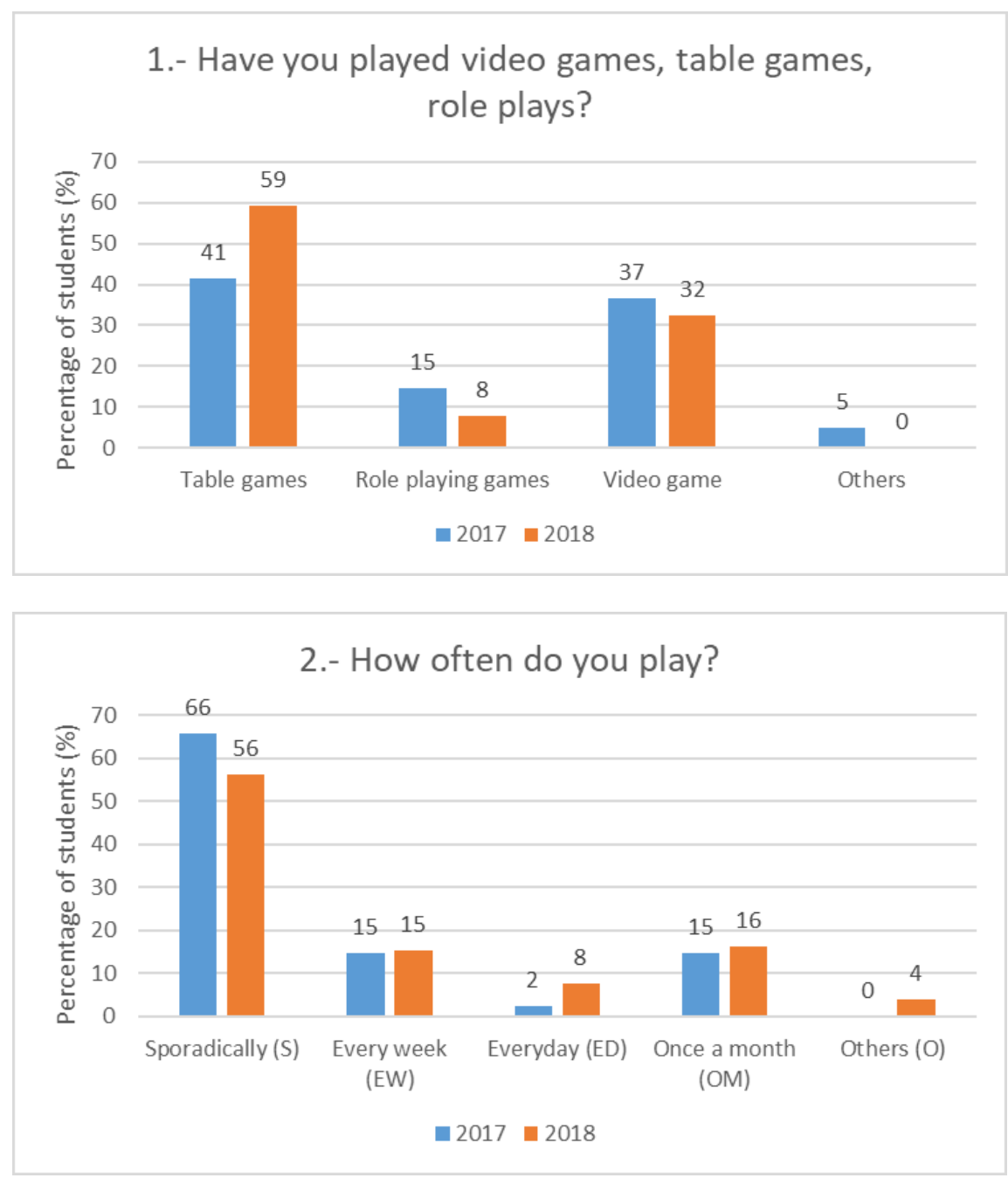

Figure 2: Knowledge about games (1) and frequency with which the students play (2). Comparison of results (percentages during courses 2017/18 and 2018/19)

Once the interest this practice could cause in our students was determined, we had to define the type of players that we could have. This is important since it has influence on the motivation, because the practice to develop would be worked on in collaborative laboratory groups, with students of very different personalities and interests. In this way, in both courses we can talk about four types of players, based on the typology defined by Bartle in 1996. These are: Achiever (or point collectors), Socialiser (interested in the relationship between groups and within the group), Explorer (focused on the operation of the game) and finally Killer (the most competitive players, focused on getting imposed on the rest). We think that a group containing a player of each type would be a balanced group. In addition, we believe since this practice is not focused on 
competitiveness but on the resolving of tests, a large number of Achiever against Killer players would produce a better development of the laboratory practice.

In the $2017 / 18$ course, after administering the questionnaire about the type of player they would like to be to the students, there was a high percentage of Achiever and Explorer players (34\% and 27\%). These data indicate that there was a non-competitive majority or a majority more interested in collecting points (Figure $3)$. In 2018/19, a part of pretest, had as an objective to define the type of players to form the teams of work. After the results of the pretest were analyzed (Figure 3), we can conclude that the groups of 4 students should work effectively, as we find more students categorized as Socialiser (34\%) and Achiever (21\%) against the students categorized as Killer (25\%). Also important is the number of students categorized as Explorer (17\%) as they will help to organize the team and coordinate the resolution of each test, as well as to comply with the rules of the game.

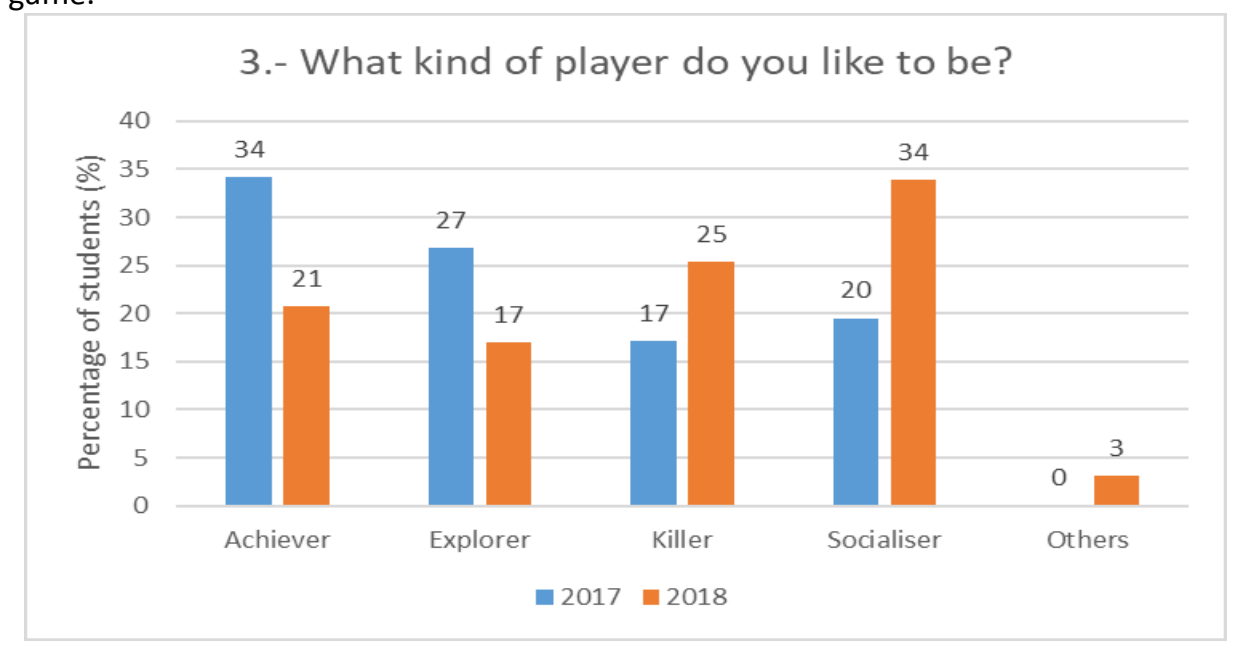

Figure 3: The type of player preferred by students who have participated in the study. Results in percentages from 2017/18 and 2018/19.

Once the target group and its characteristics have been established, the study focused on the objectives to achieve as well as procedures.

\subsection{Development of competences in Teaching Training Degree in Primary Education}

In the curriculum of the Teaching Training Degree in Primary Education at University of Alcalá, there are two subjects of pure scientific content (in $2^{\text {nd }}$ year) and one of didactic treatment of these scientific contents (in $3^{\text {rd }}$ year). The aim is not only to broaden and develop the conceptual, procedural and attitudinal competences of students in this area, but also to complement them by providing the necessary training allowing them to carry out their teaching tasks in the future, ensuring a comprehensive education of their future students in the scientific field as well.

In order to achieve this objective and to highlight the importance of the teaching-learning processes in science, teachers must acquire and develop a series of competences:

\subsubsection{Generic competences established in scientific subjects:}

All these competences are developed in laboratory practices. Nonetheless, competences 1, 3 and 6 in particular have been developed more profoundly thanks to gamified practices and to the distribution of students in cooperative groups with assigned roles.

1. To develop professional abilities such as teamwork communication ability and oral skills.

2. To strengthen the capacity for analysis and synthesis.

3. To acquire organizational and planning skills.

4. To encourage critical reasoning and autonomous learning.

5. To develop habits and skills for autonomous and cooperative learning. 


\subsubsection{Specific competences of DNS:}

Among the different competences of the subject, those specifically developed in laboratory practices are indicated below. Competencies 4 and 6 have been developed thanks to gamification since we think that they would not have been easy to achieve with another methodology. In addition, we believe those competences are essential for future teachers in order to know different ways of approaching the teaching and learning process. The best way to do so is to experience these processes themselves.

- DNS1. To know the curricular contents of the experimental sciences in Primary Education.

- DNS2. To know the difficulties inherent in the teaching-learning of science.

- DNS3. To assess the pedagogical potential of the teaching of Science and its contribution to the integral formation of the students.

- DNS4. To know and to put into practice the main teaching methodologies and strategies of teachinglearning of Sciences in the different Primary Education courses.

- DNS5. To be aware of and to know how to use the basic techniques of scientific work: observation, description, classification and experimentation.

- DNS6. To be aware of and to know how to plan the different scientific activities as well as select and elaborate didactic materials for the primary education classroom.

It is important to mention that during the 2017/18 course the students who developed the gamification practice were students who had not used this technique before. On the contrary, the students who participated in this practice during the following course were already familiar with the technique applied to laboratory practices in one of the scientific subjects. In particular, they had developed three gamified chemistry practices - therefore, some components of the gamification were already known to them, but not in an explicit way.

\subsection{Design and development of the practice}

Once the possibility of using the gamification technique has been established and its benefit and effectiveness for motivation were checked through the consulted literature, we started the design of the game for the laboratory practice. Table 1 shows the steps proposed by Werbach and Hunter (2012), followed from 1 to 3, as well as the dynamics (the SUPPOSED OR CHALLENGING starting as the initial motivating element) and the components for the whole gamification process (LEVELS AND MISSIONS; AVATARS INSIGNIA, SCORE and PROGRESS BAR or STORY-BOARD). During the previous classes, the implementation process and the script of this practice have been explained.

Table 1: Description of the steps, dynamics and components included in the experience

\begin{tabular}{|c|c|}
\hline Subject & Didactic of Natural Sciences (DNS): PRACTICE OF PALYNOLOGY \\
\hline $\begin{array}{l}\text { 1. Define objectives. "What } \\
\text { do you want to achieve?" }\end{array}$ & $\begin{array}{l}\text { General objectives: } \\
\text { - Learn to gamify a practical content for students of Primary Education } \\
\text { - Study of plants specimens, pollen, insects and the pollination process by instrumental and } \\
\text { laboratory material } \\
\text { - Develop a project through gamification study by instrumental and laboratory material of plant } \\
\text { specimens, pollen, insects, and the pollination process (developed later). } \\
\text { Specific objectives of the practice of palynology: } \\
\text { - Remember how to operate a microscope and a stereo microscope. } \\
\text { - Establish the importance of reading news and articles of scientific content. Critically analyze the } \\
\text { information and know how to use it. } \\
\text { - Know how to use dichotomous keys to identify unknown elements. }\end{array}$ \\
\hline $\begin{array}{l}\text { 2. Outline objective } \\
\text { behaviors. } \\
\text { "How are you going to get } \\
\text { it?" }\end{array}$ & $\begin{array}{l}\text { - Reading scientific and scientific-informative documents } \\
\text { - Handling laboratory instruments (microscopes and stereo microscope) } \\
\text { - Development of skills with the manipulation of mobile apps, i.e. Kahoot! }{ }^{\circledR} \text { or ClassDojo }^{\circledR}\end{array}$ \\
\hline
\end{tabular}




\begin{tabular}{|c|c|}
\hline \multicolumn{2}{|c|}{ GAMIFY COMPONENTS } \\
\hline CHALLENGE & $\begin{array}{l}\text { "The bees are disappearing and the few that remain are disoriented and do not remember their } \\
\text { work inside the hive. Therefore, we must help them remembering how they must work and thus save } \\
\text { the planet Earth ..." } \\
\text { With the explanation of the assumption students are introduced to the dynamics and receive the } \\
\text { instructions how they should work in the laboratory and how they should relate to their classmates. } \\
\text { For all practices, the same already established laboratory workgroups are kept, with cooperative } \\
\text { and assigned roles (in this case)... "You are bees and a beekeeper/scientist, the news does not give } \\
\text { good data... Throughout the practice, information will be given about how the investigations are } \\
\text { progressing". }\end{array}$ \\
\hline $\begin{array}{l}\text { ROLE OF EACH } \\
\text { STUDENT WITHIN } \\
\text { THE } \\
\text { COOPERATIVE } \\
\text { TEAM }\end{array}$ & $\begin{array}{l}\text { - Queen bee (honey bee queen): will be responsible for coordinating the group, marking the times } \\
\text { and reviewing the work done. She can delegate work to the drone bee. } \\
\text { - Drone (male honey bee): will be responsible for helping the queen bee and supervising the } \\
\text { position of the team in the progress schedule bar. They can take on some of the roles of the queen } \\
\text { bee, but only those that are assigned to them by her } \\
\text { - Worker (worker honey bee): will fulfill the script of practices and perform the manipulative work, } \\
\text { and clean the workplace } \\
\text { - Beekeeper/scientist: will write the content of the work that will be part of the script to be } \\
\text { presented as results, and will look for the clues and tests that the group has to accomplish }\end{array}$ \\
\hline $\begin{array}{l}\text { LEVELS and } \\
\text { MISSIONS }\end{array}$ & $\begin{array}{l}3 \text { levels are proposed, with a total of } 5 \text { missions, to be carried out in a single laboratory session } \\
\text { (time schedule:2 hours duration) } \\
\text { Level 1: Who or what is killing the bee population? } \\
\text { Mission 1: Alert, bees are disappearing!!!! (Reading of articles and news of scientific content about } \\
\text { the problem of the bees disappearance) (Figure 4). } \\
\text { Mission 2: Treasure hunt (Game of tracks and analysis and implementation of the information } \\
\text { consulted in the articles and scientific content news) Students shall answer questions about what } \\
\text { they have read in order to find the next clue and progress to the next level. . } \\
\text { Level 2: Importance of bees for the Earth. } \\
\text { Mission 3: Pollination and Pollen (Use of the stereo-microscope, observation of pollen preparations } \\
\text { and use of pollen identification keys) (Figure 4). } \\
\text { Mission 4: Honey plants and honey (Determination of honey plants using dichotomous keys). } \\
\text { Level 3: The honey } \\
\text { Accomplishing this level and therefore the completion of the single mission involves the satisfactory } \\
\text { resolution of a series of questions about what has been done. } \\
\text { Mission 5: Mini-Trivial Kahoot! (Self-evaluation of the practice and the end of it). }\end{array}$ \\
\hline AVATAR & $\begin{array}{l}\text { Each team is assigned an avatar that will go ahead in the process of research and search for bees } \\
\text { (Figure 4). }\end{array}$ \\
\hline BADGES & $\begin{array}{l}\text { A badge is awarded to each team when each level is completed, so that at the end of the process } \\
\text { each team can have a total of three badges (Figure } 4 \text { ). }\end{array}$ \\
\hline SCORE & $\begin{array}{l}\text { It is expected that all teams exceed the established levels, but depending on the swiftness and } \\
\text { dexterity, as well as the attitude demonstrated in each mission, they will receive more or less points } \\
\text { (represented as pollen grains). The maximum score to receive has been established at } 5 \text { points per } \\
\text { level, and the minimum at } 1 \text { point. The scoring within each level allows each team to know their } \\
\text { progress in their missions, and also check if they are working properly or not (Figure } 4 \text { ). }\end{array}$ \\
\hline STORY-BOARD & $\begin{array}{l}\text { A progress line has been designed, where each team can see the level where they are and the } \\
\text { remaining missions to be completed, providing an immediate feedback. }\end{array}$ \\
\hline
\end{tabular}

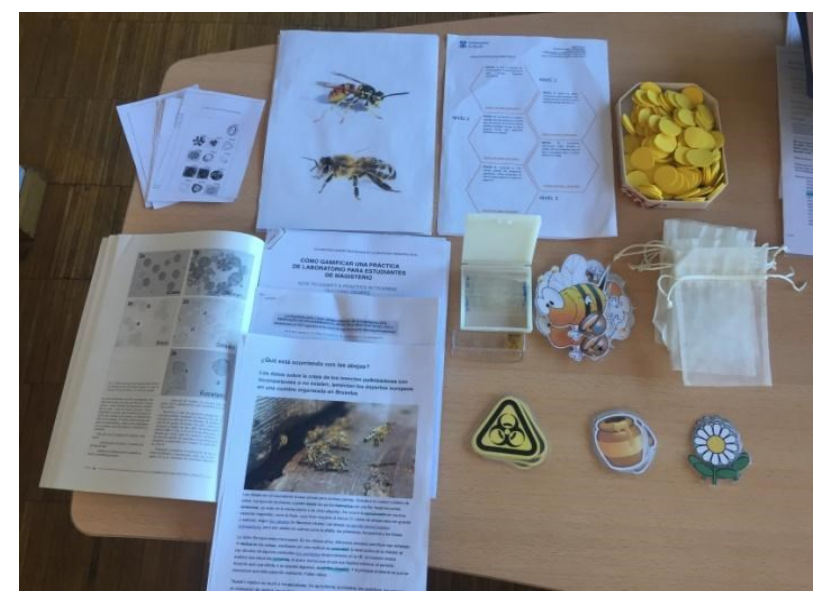

Figure 4: Components and materials created for the gamified practice of palynology 


\section{Results and discussion}

In order to evaluate the results obtained, it must be made clear that the way to collect them during the $2017 / 18$ course has been different from the 2018/19 course. During the 2017/18 course, the results of the practice were collected through the results sheets that each team had to fill out and submit, including the results of the Kahoot or final test.

During the 2018/19 course, another element has been added as a help for the teacher in order to have more reliable results, the application ClassDojo, so that each lab group could upload their evidence of completing each mission instantaneously, and the teacher could compare it with the result sheet submitted at the end of the practice (Figure 5, left).

Both of these mobile applications (Kahoot and ClassDojo) are recommended for gamification. ClassDojo is normally used in primary and secondary education. This application shows an interface appropriate for children where they pretend to be a monster (avatar), and where they can collect points as they progress in achieving goals. The teacher is the one that assigns points, and the possibility exists to let the parents participate. Cigdem and Cizem (2013) in their research discuss how the motivation can increase if you use applications like ClassDojo in the science class. It is also important to be able to incorporate the parents of the students in their day to day activities. Kahoot has been used in the two courses in which the gamification practice has been developed. In the last mission (Mission 5), Kahoot has been implemented as a final test by the way of self-assessment in the lab practice. According to the students, the easiest mission was mission 5 , this at the same time being the most competitive mission.

Finally, the students had to record their results in a final report (Figure 5 left). They had to mark the levels and missions achieved in the report. The students had to submit the results sheet of the practice by teams with the improvement and elaboration of each one of the established missions.
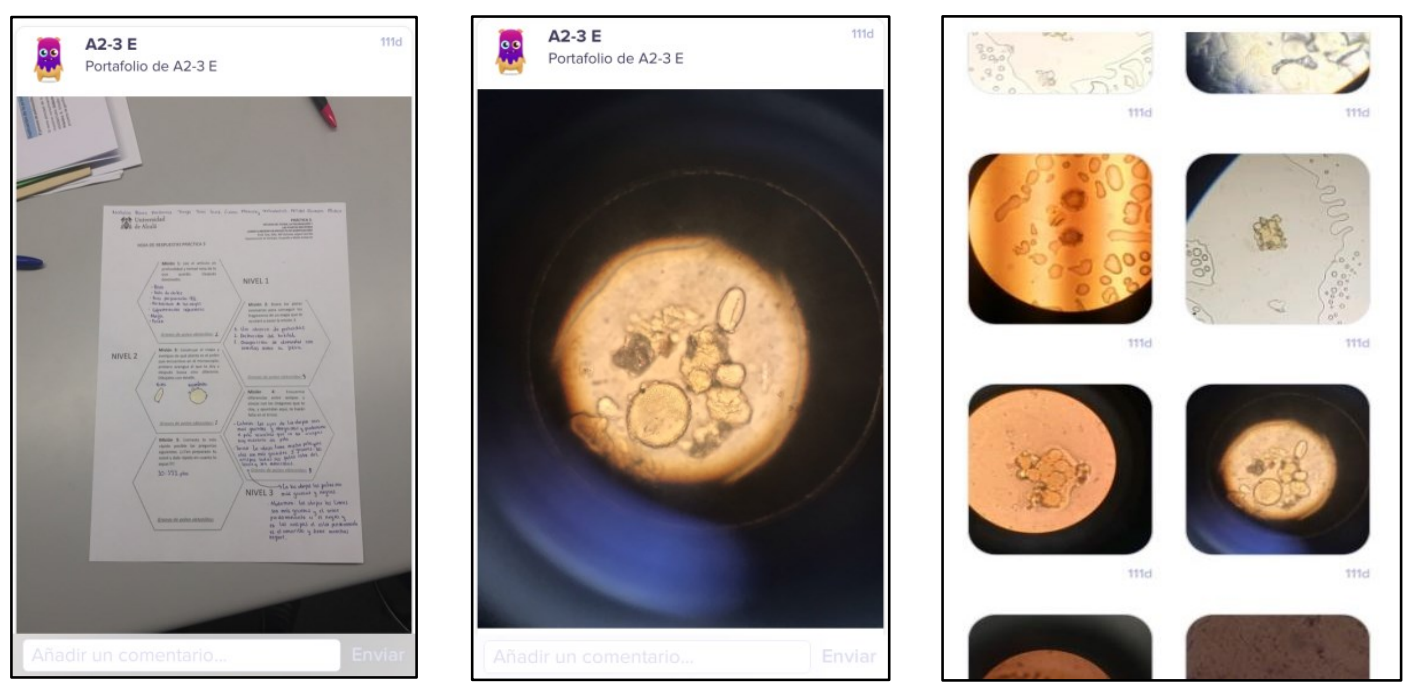

Figure 5: Images of ClassDojo application with the evidence collected from Mission 3.

Left: Sheet of Practice Lab group results. Center: Photographic evidence of the pollen observation with the stereo-microscope that one of the groups uploaded to ClassDojo. Right: photographic evidence of the observation of the rest of groups, collected in ClassDojo

When we reviewed the reports of submitted laboratory practices, they proved that $100 \%$ of students have passed the proposed missions. However, the most complete mission has been the mission that involved the use of a microscope without the teacher's help, identification of pollen with dichotomous keys and scientific drawing (they should remember the procedures for each action studied previously). 

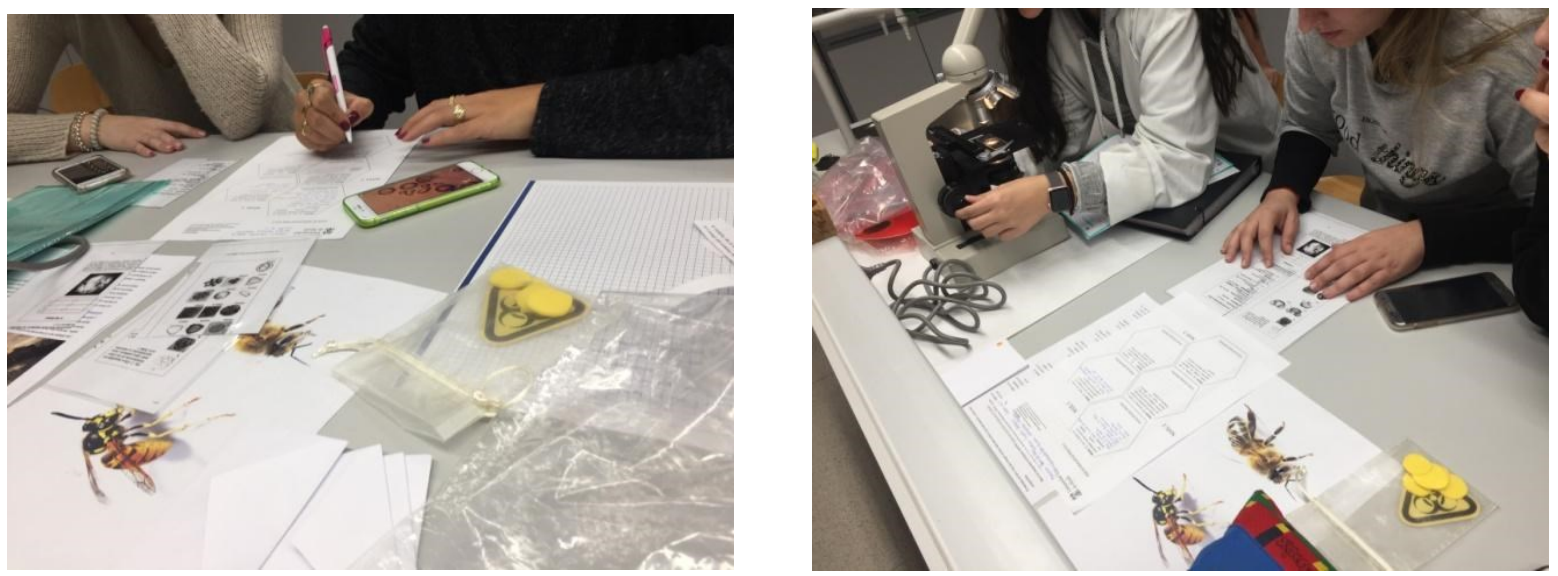

Figure 6: Images during the practice process. Students developing the proposed Mission3, development of scientific competence. Picture 6 right: A student is filling out the answer sheet using a photo taken by the mobile of what she has seen in the stereo-microscope. Picture 6 left: While a student observes the pollen sample using stereo-microscope, the rest of the team builds the dichotomous key obtained in the previous mission in order to identify the specimen they are observing with the microscope

\subsection{Motivation}

There has been a $96 \%$ class attendance in both courses that participated in the study, despite knowing that the practice did not count towards the total qualification of the subject. This shows that the motivation has worked. In total, 41 collaborative working groups of 3 or 4 components in 2017/18 and 48 in 2018/19 with specific work roles assigned to each participant have taken part in this project. In fact, when we asked what the most important part of the gamification was, $56 \%$ have answered motivation, placing it above the team work and the necessity to feel integrated into a team (Figure 7).
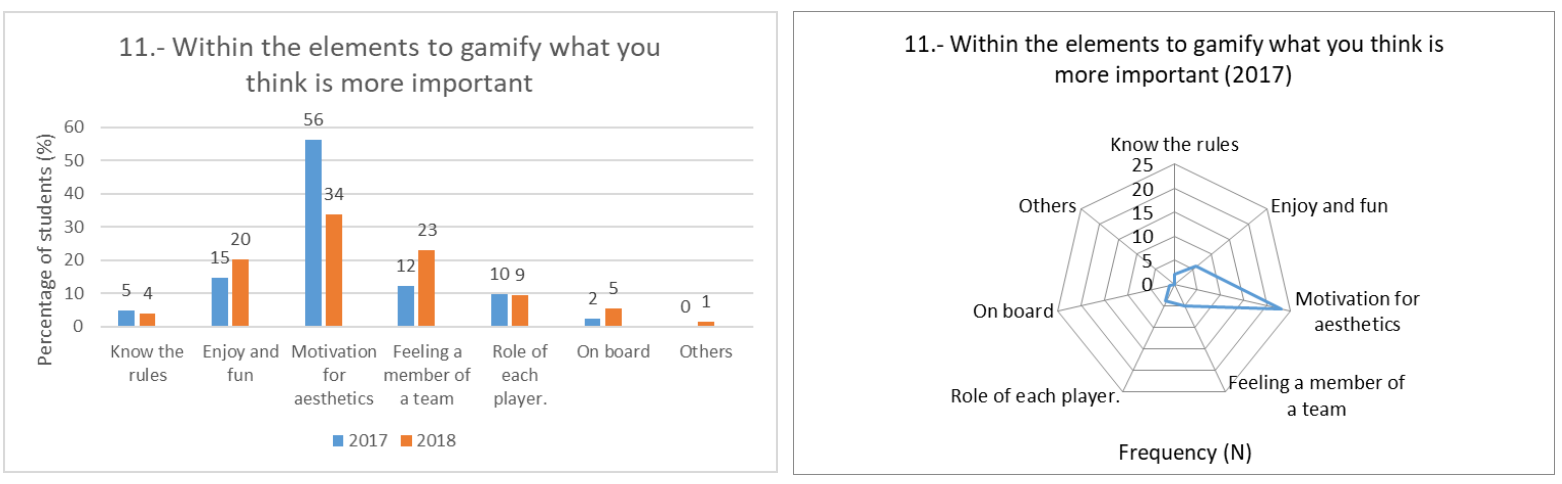

Figure 7 (right, left): Within the elements to gamify which one you think is more important

In addition, the impressions of the students were assessed and analyzed. The Google forms questionnaires were rated to check the type of student (player) that had participated in the gamified practice and to check if the dynamics were occurring as expected. This questionnaire has been completed by 41 of 150 students during the 2017/18 course, and by 74 of 180 students in 2018/19 course. In 2017/18 course, regarding the studentplayer type, $80 \%$ had played table games or video games, and approximately $15 \%$ had played role-play games and therefore they were mostly familiar with the dynamics and elements of the game. Accordingly, we must say of that of all the students who answered the survey, only $15 \%$ played every week, while $67 \%$ did so sporadically.

In $2017 / 18$ course, despite being knowledgeable about the games, more than $80 \%$ of students did not know that this technique can be applied to education; hence it has been quite a discovery for them. There is also a hope that they would apply the technique in their future classes. In the question about the type of player they would like to be, the answers have been balanced, although there is a $35 \%$ group that surpasses the rest, stating that they like to be Achiever or Point collectors as motivation after resolving the challenge (Bartle, 
1996). This means that we were successful when assigning roles, since in each group there could be between 1 and 2 players of this type.

With regard to the opinions of the students gathered after the practice in both academic years, two questions were prepared in order to verify that the design of the practice had been appropriate. One was taking into account the type of players, their allocation in collaborative groups and the components chosen for gamification. When students have been asked about the part of the practice or mission that they liked the most, the most common answer by far was the most dynamic part or game of tracks, although the resolution of scientific tests (such as use of a microscope, or use of dichotomous keys) was the second best valued (Figure 8). The other question was: Within the elements to gamify what you think is more important? (Figure 7).

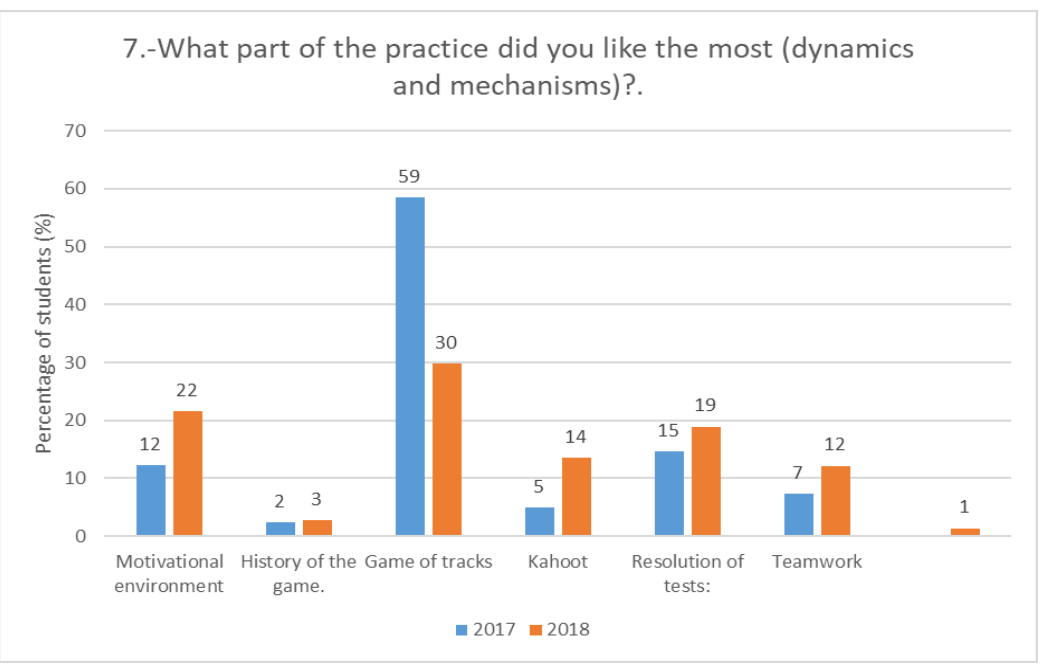

Figure 8: Graph that shows the answers to the question: What are the dynamics or mechanisms of the gamify practice that you liked the most?

Data in Table 2 (relative to the 2017/18 course) show the part of practice that students liked the most (Figure 8). 15 out of 23 students who have chosen motivation for aesthetics of the game (Figure 7) stated that they preferred the game of tracks (GT), regardless of type of player and the frequency with which they played. We can therefore conclude that the students were attracted by the motivational and aesthetic part of the game and within it by the part where they had to think critically, work in groups or cooperate with other students. We believe that this is caused by the fact that they are familiar with these types of interaction. Moreover, this was also the option chosen by the majority (59\%) of the students.

Table 2: Characteristics of the 23 students (56\%) of 2017/18 course who answered that the most important element of the game (question 11) was the motivation produced by its aesthetics

\begin{tabular}{|l|l|l|l|l|}
\hline TYPE OF PLAYER & TABLE GAMES & ROLE & VIDEO GAME & OTHERS \\
\hline Achiever & $3 S(1 \mathrm{MA}+2 \mathrm{GT})$ & $1 \mathrm{~S}(\mathrm{~K})$ & $1 \mathrm{~S}(\mathrm{GT})$ y 1 EW (GT) & $2 \mathrm{OM}(1 \mathrm{GT}+1 \mathrm{RT})$ \\
\hline Explorer & $4 \mathrm{~S}(1 \mathrm{MA}+3 \mathrm{GT})$ & & $3 S(1 \mathrm{MA}+2 \mathrm{GT})$ & \\
\hline Killer & & $10 \mathrm{M}(\mathrm{GT})$ & $1 \mathrm{~S}(\mathrm{GT})$ & \\
\hline Socialiser & $1 \mathrm{~S}(\mathrm{GT})$ & $1 \mathrm{~S}(\mathrm{GT})$ & $\begin{array}{l}2 \mathrm{~S}(\mathrm{MA}+\mathrm{GT}), 1 \mathrm{EW}(\mathrm{RT}), \\
1 \mathrm{ED}(\mathrm{GT})\end{array}$ & \\
\hline
\end{tabular}

Table Legend: Sporadically (S); Every week (EW); Everyday (ED); Once a month (OM); Motivational atmosphere (MA); History (H); Game of tracks (GT); Kahoot (K); Resolution of tests (RT)

In the 2018/19 course, the majority of the students also chose the motivational options for aesthetics (Figure 7) and game of tracks. However, the percentage of "Motivation for aesthetics" in the Figure 7 fell considerably from $56 \%$ in $2017 / 18$ course to $34 \%$ in $2018 / 19$ course, sharing place with the options "Enjoy and have fun" (20\%) and "The need to feel as a member of a team" (23\%). The percentage of "track set" in Figure 8 decreased from $59 \%$ in $2017 / 18$ course to $30 \%$ in $2018 / 19$ course, as the percentages of these options increased: 
Motivational atmosphere (22\%); Kahoot (14\%); Resolution of tests (19\%) and Cooperative work (12\%). Specifically 24 students of the 77 who completed the 2018 posttest, chose "aesthetic motivation". Of them, 9 students chose OM (once a month), 2H (history), $6 \mathrm{GT}$ (game of tracks); 1K (Kahoot), 5RT (resolution of tests), 1 Cooperative Work.

These variations can be attributed to two causes: a different profile distribution of players of the years 2017 and 2018; and the fact that the students of 2018 already knew the gamification technique since they made two laboratory sessions in other subject (Matter and Energy Sciences in the second year).

\subsection{Objectives and skills improvement}

The most developed competences proposed in the subject are the generic competences associated with autonomous work and cooperative teamwork. In addition, to achieve the objectives of the game, the planning and the organization of the teamwork were developed in an optimal way. One of the didactic objectives of the practice was that the students become familiar with the technique, as well as the way of designing a gamified content. In 2017/18 course the students were less familiar with the technique, with $80 \%$ of the students classifying the use of this application for education as unknown. The innovation project that supports this research involves laboratory practices in other scientific subjects, so that students in the 2018/19 course have already applied gamification in chemistry class in the previous course. Therefore, in this course we had students who were more accustomed to the same technique.

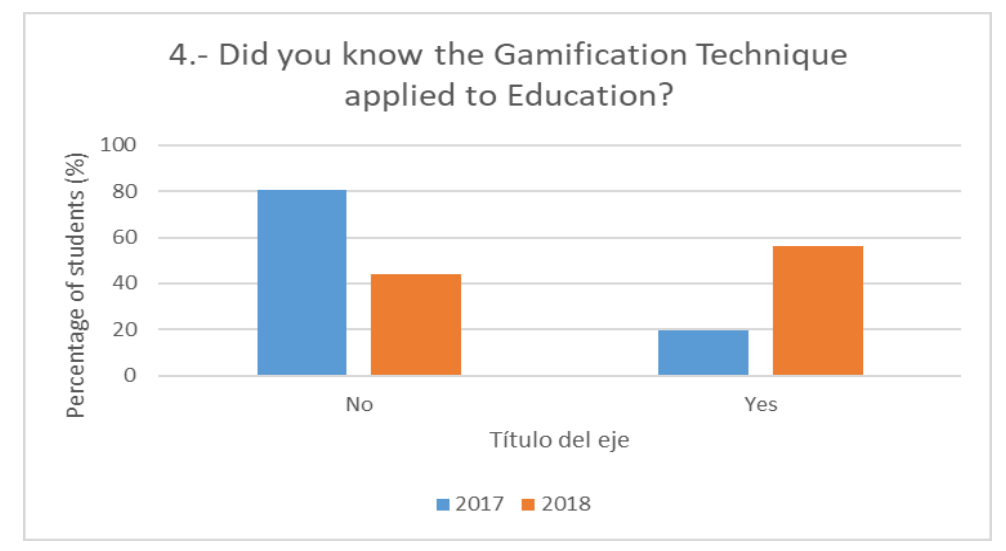

Figure 9: Graph that shows the answers to the question: Did you know the Gamification Technique applied to Education?

In addition, we wanted to know if after becoming familiar with the elements, dynamics and mechanisms, students considered themselves capable of generating this type of practice. Consequently, they were asked another question to establish if they would be able to gamify a content of their class. The majority of the students said YES (Figure 10), and many of them have applied this technique in their syllabus design. Therefore, we can establish that the objective has been reached.

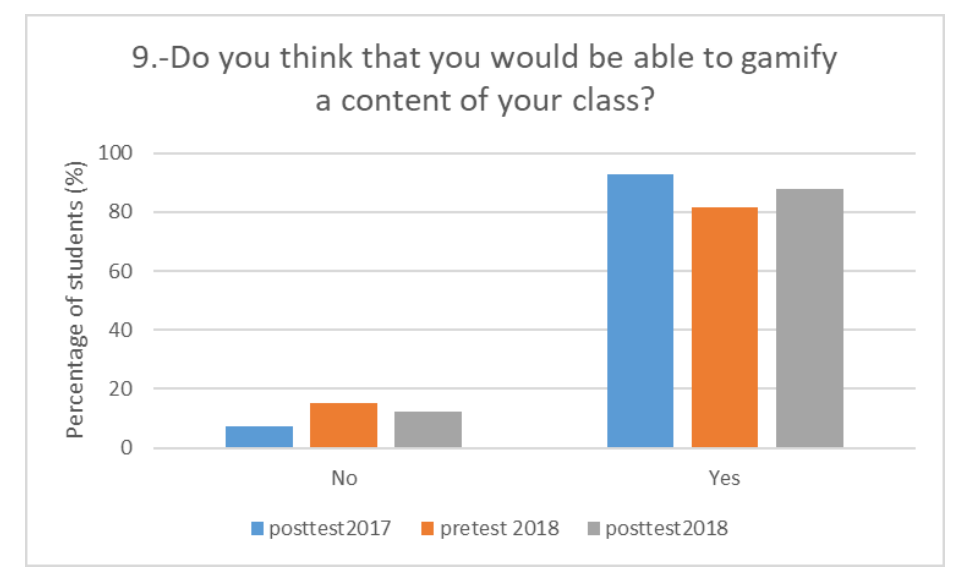

Figure 10: Graph that shows the answers to the question: Do you think that you would be able to gamify a content of your class? 
Finally, the reports of students show that the most worked scientific skills have been observation, detailed description and information analysis.

\section{Conclusions}

Recent studies mapping existing literature generally came to the conclusion that there is a growing interest in gamifying educational content but there is a lack of empirical evidence to support claims about positive impacts on learning outcomes. Since research on gamification in education is still developing, this study aims to offer a new evidence. This lack of evidence for the efficacy of gamification is not specific to science education but to higher education in general (Fleischmann and Ariel, 2016).

We first summarize here the theoretical basis of gamification and its main components and dynamics, focused in the Education context. Secondly, a gamification of laboratory practices in a subject from the curriculum for the Teaching Training in Primary Education degree (Didactics of Natural Science (DNS), 3rd year) is presented and evaluated. It was developed in two consecutive academic years: 2017/2018 (5 groups, 150 students' enrollment) and 2018/2019 (6 groups, 183 students' enrollment). We agree with Drace (2013) that any laboratory practice has the potential to be gamified because this method changes intrinsic motivations of the students and not require to renew the materials or modify the objectives to be fulfilled by the students.

Several tools suitable for gamification have been tested. We can further conclude that the application ClassDojo helps the teacher to collect all the evidence and to check the lab results of paper reports. Consequently, we found that ClassDojo can help the teacher and the students become more aware of their own work (Chiarelli, Szabo and Williams, 2015). The reports presented by the laboratory groups show the achievement of the objectives and therefore the achieving of proposed missions. However, it has been shown that the quality of work presented is not excellent in general; especially in instrumental manipulation (microscopes) and identification of pollen and plants through dichotomous keys. Kahoot has also been used to collect the responses for the last mission. We could state that accomplishing this mission demonstrated that students are highly competent in the use of the application and motivated by its competitive and ludic character. Since quick responses are required, competitiveness is promoted at the same time (the fastest group, the smartest group, the one that has performed the best...). Therefore, using Kahoot has increased the competitive spirit and therefore the participation in the laboratory, in agreement with previous studies (Wang and Lieberoth, 2016).

We conclude that gamification influences motivation through the elements proposed to carry out practice. However, we have not proved yet that the learning had been significant. To this achievement, it is critical an adequate game design since otherwise learning can be influenced by manipulation and competitiveness, but the significant learning is not achieved. Thus, motivation exists, but the objective is lost. Hence, we think that we must continue with this line of work that has already advanced in the accomplishment of laboratory practices.

Finally, the students had to present a syllabus design as their final project. Three of groups from 2017/18 course and four groups from 2018/19 course presented their programs for practices of Biology or Geology based on the technique of gamification. Therefore, the objective of mastering the technique and learning to design projects based on it has been fulfilled.

As final conclusion we could state that the main objectives has been met, i) the gamification methodology has been successfully applied to lab practices, ii) it has been shown that this methodology fosters the students motivation and, iii) the students have learned the technique improving their skills for their future professional development. On the other hand, we cannot assure that gamification makes the student learn better but it allows to work mores competences than a normal practice.

\section{Acknowledgements}

This work is a contribution to the Teaching Innovation Project of the University of Alcalá UAH/EV969, entitled: Gamification in the Science Laboratory: a new approach to natural science practices in the Faculty of Educationand its extension UAH/EV985.

We would like to thank Slavka Madarova for her help with translating this document. 


\section{References}

Bartle, R.A. (1996). "Hearts, Clubs, Diamonds, Spades: Players Who Suit MUDs". Journal of MUD Research, Vol.1, No. 1. Chiarelli, M., Szabo, S. \& Williams, S. (2015).Using Classdojo to help with Classroom management during guided reading. Texas Journal of Literacy Education, Vol. 3, No. 2, pp 81-88.

Deterding, S., Dixon, D., Khaled, R. \& E. Nacke, L. (2011). Gamification: Toward a definition. Gamification Workshop Proceedings, Vancouver 2011. Pp 12-15.

Dicheva, D., Dicheva, C., Agre, G. \& Angelova, G. (2015). Gamification in education: A systematic mapping study. Educational Technology \& Society. Vol.18, No.3, pp 75-88.

Drace, K. (2013). Gamification of the Laboratory Experience to Encourage Student Engagement.Journal of Microbiology and Biology education (J Microbiol Biol Educ.) Vol.14, No.2, pp 273-274.

Fleischmann, K. \& Ariel, E. (2016). Gamification in Science Education: Gamifying Learning of Microscopic Processes in the Laboratory. Contemporary Educational Technology, Vol.7, No. 2, pp 138-159.

García-Tormo, J.V. (2018). Aplicación de TICS (formularios on-line) como metodología docente activa en Estudios de Postgrado.International Journal of Developmental and EducationalPsychology INFAD Revista de Psicología, №1 Monográfico 2, pp.199-208.

Hamari, J., Koivisto, J. \& Sarsa, H. (2014). Does Gamification Work? - A Literature Review of Empirical Studies, 47th Hawaii International Conference on System Science. Pp 3025-3034.

Hursen, C. \& Bas, C. (2019). Use of Gamification Applications in Science Education. International Journal of Emerging Technologies in Learning (iJET). Vol.14, No. 1, pp 4-23.

Iosup, A. \&Epema, D. (2014). An Experience Report on using Gamification in teaching higher education. Proceedings of the 45th ACM technical symposium on Computer science education. Pp 27-32.

Kim, B. (2015). Understanding Gamification. ALA Editions, Chicago.

Lopez Carrillo, D., CalongeGarcía, A., Rodríguez Laguna, T., RosMagán, G. Andrade Olalla, A. \& Moreno Lebrón, A. (2018). Game Based learning in Laboratory Practice. 17th Proceedings of the European Conference on e-Learning, ECEL. Pp 322-328.

Nah, F.-H., Zeng, Q., Telaprolu, V., R., Ayyappa, A. P.\&Eschenbrenner, B. (2014). Gamification of education: a review of literature. $\mathrm{HCl}$ Business. Pp 401-409.

Morris, B., Croker, S., Zimmerman, C., Gill, D., \&Romig, C. (2013). Gaming science: the "Gamification" of scientific thinking. Frontiers in psychology, Vol. 4, No. 607.

Rodríguez, F. \& Santiago, R. (2015). Gamificación: Como motivar a tu alumnado y mejorar el clima en el aula. GrupoOcéano, Madrid.

Sailer, M., Hense, J. Mandl, H. \&Klevers, M. (2013). Psychological Perspectives on Motivation through Gamification. Interaction Design and Architecture(s) Journal (IxD\&A) N.19, pp 28-37.

Sánchez iPeris, F. J. (2015). Gamificación. Education in The Knowledge Society (EKS). Vol. 16, No. 2, pp 13-15.

Wang, A.I. \& Lieberoth, A. (2016). The effect of points and audio on concentration, engagement, enjoyment, learning, motivation, and classroom dynamics using Kahoot!.European Conference on Games Based Learning, 2016.

Werbach, K. \& Hunter, D. (2012). Gamificación, revoluciona tu negocio con las técnicas de los juegos. Pearson, Madrid. Zichermann, G. \& Cunningham, C. (2011). Gamification by design: Implementing Game Mechanics in Web and Mobile Apps. O’Reilly Media. 